\title{
EDITORIAL
}

\section{Special ISOT issue on ocular trauma}

\author{
Ferenc Kuhn
}

Received: 21 January 2009 /Accepted: 27 January 2009 /Published online: 17 February 2009

(C) Springer-Verlag 2009

Keywords Trauma $\cdot$ Journal $\cdot$ Graefe's $\cdot$ Springer

Many years ago, I actively pursued the launch of a journal dedicated solely to ocular traumatology, even had a title for it: "Journal of Eye Trauma" (JET). My drive for this journal followed a long and hard debate among our small group of trauma-enthusiast ophthalmologists as to whether it is preferable to have a separate journal to feature exclusively trauma articles or to continue "dispersing" such articles in a wide variety of existing journals.

Both approaches have advantages and downsides. Having a dedicated trauma journal implies that all who are interested in the subject gain instant access to the best articles in the field. In reality, this group includes even those ophthalmologists who claim not be interested: trauma knows no boundaries, and no practicing ophthalmologist can be shielded from being exposed to patients with eye injuries. However, a separate eye trauma journal also means that ophthalmologists are obliged to subscribe to yet another publication, as if they hadn't had (too) many to subscribe to already.

Conversely, lacking such a dedicated journal those with special interest in ocular traumatology must review many, many publications to make sure that they are able to read all new information published in this rapidly changing field.

After long, sometimes heated discussions, we concluded that the advantages of such a dedicated journal probably outweigh its disadvantages. This was especially true in an era

F. Kuhn $(\bowtie)$

Helen Keller Foundation for Research \& Education,

1201 11th Ave South Ste 300,

Birmingham, AL 35205, USA

e-mail: fkuhn@mindspring.com when the internet was much less advanced and accessible than it is today. Hence, I started the long process of identifying those publishers I presumed would be interested in the Journal of Eye Trauma and my negotiations with a few of these publishers commenced.

The process was long and arduous, and over time I became very disappointed. I was unable to identify a publisher who would accept the financial risk of starting the journal. Every publisher that I approached said that they would be willing to consider it as long as I had a sufficient number of subscribers-paid subscribers, that is; no publisher had the courage to invest without a guaranteed return on it.

My enthusiasm never waned; however, our society's (International Society of Ocular Trauma, ISOT) budget, which is much smaller than that of any of the international publishers I approached, did not permit us to take on the risk. And since I had so many other projects that attracted my attention, energy, and time, I shelved the trauma journal idea for well over a decade.

When the leadership of Graefe's and Springer graciously agreed to provide a special forum to the field of ocular traumatology a little while back, by offering to run an annual issue completely or at least in part dedicated to ocular traumatology, I became convinced that this offer represents an ideal compromise between the two possible options discussed above.

Graefe's is the world's oldest ophthalmological periodical. It is highly respected internationally and has a wide reach. It also has the same basic characteristic that injury does: it is not restricted to any subspecialty such as cornea or lens or retina, but cuts across all subspecialties. If any ophthalmologist wants to do an excellent job (and who wouldn't?) in restoring the injured eye's anatomy-a 
prerequisite to functional improvement - that ophthalmologist must have a knowledge base encompassing not a single tissue but the eye as a whole. "Nil nocere" means not only that you don't inflict additional injury on the eye but also that you accomplish all that can be accomplished. For this, you need training, dedication, commitment-and information on the latest developments; for this, you need Graefe's.

In our inangural trauma issue, we offer a wide spectrum of articles from epidemiology to management, from diagnostics to therapy, from the cornea to the retina. We can read about the potentially devastating consequences of a new, increasingly popular sport ("paintball") in the US by Pahk and Adelman; about the trauma to children caused by "toy guns" in Kuwait by Bouhaimed et al.; and about the dangers of corks and caps on bottles containing pressurized fluid - this Italian report by Cavallini et al. is the largest series published so far.

A unique article is also presented to the reader on the use of a fairly new device in our diagnostic armamentarium, the optical coherence tomograph, from Wylegala et al. in Poland. Rüfer et al. from Germany describe their experiences in implanting an iris claw lens behind, rather than in front of, the iris; and, finally, Rossi et al. from Italy present a study on a major surgery, combining iris diaphragm reconstruction with vitrectomy.

A truly international panel of experts sharing their experience in different aspects of restoring sight to the severely injured patient - this is what the current issue of Graefe's offers. We invite those interested in ocular traumatology to continue submitting their best work to this dedicated journal, and look forward to its 2010 trauma issue. 